\title{
IDENTIFIKASI Neisseria gonorrhoeae PADA PEKERJA SEKS KOMERSIAL DI PANTI SOSIAL MATTIRODECENG MAKASSAR Mursalim ${ }^{1}$, Syahida Djasang ${ }^{1}$ \\ 1) Jurusan Analis Kesehatan
}

\begin{abstract}
ABSTRAK
Penelitian ini berlatar belakang Infeksi Menular Seksual (IMS) sampai saat ini masih merupakan masalah kesehatan masyarakat di seluruh dunia, baik di negara maju (industri) maupun di negara berkembang. Pekerja seks komersial dewasa ini dianggap merupakan penyebab utama penyebaran penyakit menular seksual. Tujuan penelitian ini adalah untuk mengidentifikasi Neisseria gonorrhoeae pada pekerja seks komersial di Panti Sosial Mattirodeceng Makassar. Jenis Penelitian ini adalah observasi laboratorik yang bersifat deskriptif Berdasarkan hasil penelitian ini dari 15 sampel tidak ditemukan Neisseria gonorrhoeae pada pekerja seks komersial di Panti Sosial Mattirodeceng Makassar. Dari hasil penelitian diatas disarankan untuk mencegah penularan Neisseria gonorrhoeae senantiasa menggunakan kondom atau seks aman. Setia kepada pasangan atau tidak berganti - ganti pasangan.
\end{abstract}

Kata kunci : Neisseria gonorrhoeae, PSK

\section{PENDAHULUAN}

World Health Organization ( WHO ) memperkirakan setiap tahun terdapat 350 juta penderita baru Penyakit Menular Seksual (PMS) di negara berkembang seperti di Afrika, Asia, Asia Tenggara, dan Amerika Latin. Di negara industri prevalensinya sudah dapat diturunkan, namun di negara berkembang prevalensi gonore menempati tempat teratas dari semua jenis PMS. Dalam kaitannya dengan infeksi HIV/AIDS, United States Bureau of Census pada 1995 mengemukakan bahwa di daerah yang tinggi prevalensi PMS-nya, ternyata tinggi pula prevalensi HIV/AIDS dan banyak ditemukan perilaku seksual berisiko tinggi. Kelompok seksual berperilaku berisiko tinggi antara lain Commercial Sex Workers (CSWs). Berdasarkan jenis kelaminnya, CSWs digolongkan menjadi Female Commercial Sexual Workers (FCSWs) 'Wanita Penjaja Seks' (WPS) dan Male Commercial Sexuall Workers (MCSWs). (idmgarut.wordpress.com. 2009 ).

Mata rantai penularan penyakit hubungan seksual adalah pada pekerja seks komersial ( PSK ) yang dapat menyusup dalam kehidupan rumah tangga. Perubahan perilaku seksual telah menyebabkan timbulnya berbagai masalah yang berkaian dengan penyakit hubungan seksual dan kehamilan yang tidak di kehendaki. Penyakit hubungan seksual dapat menimbulkan infeksi akut yang memerlukan penanganan yang tepat oleh karena akan menjalar ke alat genitalia bagian dalam dan dapat menimbulkan penyakit radang panggul, pengobatan yang tidak memuaskan akan dapat menjadikan kronis dengan akibat akhir rusaknya fungsi alat genitalia bagian dalam sehingga menimbulkan kurang subur atau mandul. Dalam pertemuan di Atlanta USA, tentang penyakit hubungan seksual, menyatakan bahwa mata rantai yang di tularkan oleh Wanita Tuna Susila (WTS) tidak dapat dihilangkan, akan tetapi hanya mungkin di perkecil peranannya. (Nurivina, 2012 ).

Dua metode untuk mendeteksi $N$. gonorrhoeae adalah tes cultur dan non non cultur. Teknik kultur dianggap sebagai tes pilihan; tetapi teknik nonkultur juga memiliki ketepatan yang sama dengan teknik kultur. Beberapa contoh. Teknik nonkultur terbaru adalah tes amplifikasi asam nukleat. Tes ini memiliki sensitivitas yang baik (9296 persen) dan spesifitas (94 hingga 99 persen) dibandingkan dengan cultur.

Neisseria gonorrhoeae adalah obligat patogen manusia dan merupakan agen etiologi gonore. Sindrom termasuk servisitis pada wanita, dan uretritis, faringitis dan proktitis pada kedua jenis kelamin. Jika tidak diobati, wanita mungkin mengalami sekuel yang parah dari penyakit radang panggul, nyeri panggul kronis, kehamilan ektopik dan infertilitas tuba, sementara pria dapat mengembangkan epididimitis, prostatitis dan striktur uretra.(LCDC).

PSK dewasa ini dianggap merupakan penyebab utama penyebaran penyakit menular seksual. Dikarenakan prilaku sex yang berganti - ganti pasangan, melakukan sex yang tidak aman (tidak menggunkan kondom). Berdasarkan uraian latar belakang penelitian ini maka dapat dirumuskan sebagai berikut : Apakah pekerja seks komersial yang ditampung di panti sosial Mattirodeceng Makassar terinfeksi Neisseria gonorrhoeae?.

$$
\text { Tujuan penelitian ini adalah Untuk }
$$
mengidentifikasi Neisseria gonorrhoeae pada 
pekerja sex komersial di Panti Sosial Mattirodeceng Makassar.

\section{Metode Penelitian}

Jenis penelitian yang dilakukan adalah observasi laboratorik yang bersifat deskriptif yakni melakukan pemeriksaan Neisseria gonorrhoeae pada pekerja seks komersial.

Populasi dalam penelitian ini adalah Semua pekerja seks komersial. Sampel yang digunakan dalam penelitian ini adalah pekerja seks komersial di Panti Sosial Mattirodeceng Makassar sebanyak 15 sampel. Tehnik pengambilan sampel yaitu accidental sampling.

Pengambilan spesimen, Pasien diberi penjelasan tentang tindakan yang akan dilakukan.Alat dan bahan yang diperlukan disiapkan. Pasien diposisikan terlentang dengan kedua lutut ditekuk ( posisi litotomi ). Speculum steril dimasukkan dengan hati - hati dan speculum dibuka.ujung kapas lidi diileskan pada daerah endoserviks, gerakan lidi melingkar kekanan dan didiamkan beberapa saat untuk penyerapan.

Sekret yang didapat dioleskan pada kaca objek untuk dibuat preparat. Kapas lidi dimasukkan pada media Stuart dan ditutup kemudian dilabel untuk dikirim ke laboratorium. Spesimen ditanam langsung pada media Coklat Agar Plate ( Janda WJ dkk). Spesimen yang berasal dari secret vagina diambil dengan swab khusus, digulirkan pada permukaan agar Coklat agar, biasanya digulirkan dengan bentuk zig - zag. Media yang telah ditanami dimasukkan kedalam kaleng / anaerobic jar, yang kedalam anaerobic jar itu juga dimasukkan kapas basah dan lilin menyala. Setelah kaleng / anaerobic jar ditutup rapat, lilin padam, kemudian dimasukkan ke inkubator $36^{\circ} \mathrm{C}$ selama 48 jam. (Jeanne $M$. Marrazzo $d k k$ )

Pengamatan koloni pada media coklat agar Koloni gonokokus berbentuk cembung berkilau, meninggi dan sifatnya mukoid berdiameter $1-5$ $\mathrm{mm}$. Koloni transparan atau pekat, tidak berpigmen dan tidak bersifat hemolitik. Oksidase test, Koloni yang tumbuh digoreskan pada kertas test oksidasi. Didiamkan selama \pm 2 menit, kemudian dibaca. Positif : bila terbentuk warna biru

Pengecatan Gram, Kaca objek dibersihkan, sehingga bebas lemak. Pada bagian ujung kaca objek diberi tanda, sebaiknya disebelah permukaan yang tidak dicat. Dengan ose dibuat preparat yang tipis pada permukaan yang telah dibersihkan.
Preparat dikeringkan diudara. Fiksasi dilakukan dengan cara menyentuhkan permukaan kaca objek tiga kali berturut - turut pada ujung api bunsen. Setelah didinginkan preparat siap untuk dicat. Larutan Karbol gentien violet dituang diatas preparat, didiamkan selama 30 detik. Preparat dicuci dengan air mengalir. Tuang larutan lodium dan dibiarkan selama 30 detik. Bilas dengan air mengalir. Preparat didekolorisasi dengan aceton alkohol sampai semua warna tampak luntur dari preparat. Bilas dengan air mengalir. Preparat diberi warna kontras seperti safranin. Diamkan selama 30 detik. Bakteri gram positif apabila berwarna ungu, Bakteri gram negatif : apabila berwarna merah.

Koloni disubculture pada chokelat agar plat, atau chokelat agar plate atau BAP, inkubasi pada suhu $37^{\circ} \mathrm{C}$ selama 24 jam tanpa atau dengan $\mathrm{CO}_{2}$ untuk proses identifikasi. Koloni yang tumbuh di subculture ditanam pada media fermentasi karbohidrat, diinkubasi pada suhu $37^{\circ} \mathrm{C}$ selama 24 jam tanpa atau dengan $\mathrm{CO}_{2}$.

\section{Hasil.}

Berdasarkan hasil penelitian laboratorium yang dilakukan di Balai Besar Laboratorium Kesehatan Makassar pada sampel swab vagina pekerja seks komersial di Panti Sosial Mattirodeceng Makassar diperoleh hasil sebagai berikut:

Tabel Hasil Identifikasi Neisseria gonorrhoeae pada PSK di Panti Sosial Mattirodeceng Makassar

\begin{tabular}{|l|c|c|c|}
\hline No & $\begin{array}{c}\text { Nomor } \\
\text { sampel }\end{array}$ & $\begin{array}{c}\text { Hasil } \\
\text { Neisseria } \\
\text { gonorrhoeae }\end{array}$ & Keterangan \\
\hline 1 & 14106047 & $\begin{array}{c}\text { Tidak ada } \\
\text { ditemukan }\end{array}$ & Negatif \\
\hline 2 & 14106048 & $\begin{array}{c}\text { Tidak ada } \\
\text { ditemukan }\end{array}$ & Negatif \\
\hline 3 & 14106049 & $\begin{array}{c}\text { Tidak ada } \\
\text { ditemukan }\end{array}$ & Negatif \\
\hline 4 & 14106050 & $\begin{array}{c}\text { Tidak ada } \\
\text { ditemukan }\end{array}$ & Negatif \\
\hline 5 & 14106051 & $\begin{array}{c}\text { Tidak ada } \\
\text { ditemukan }\end{array}$ & Negatif \\
\hline 6 & 14106052 & $\begin{array}{c}\text { Tidak ada } \\
\text { ditemukan }\end{array}$ & Negatif \\
\hline 7 & 14106053 & $\begin{array}{c}\text { Tidak ada } \\
\text { ditemukan }\end{array}$ & Negatif \\
\hline 8 & 14106054 & $\begin{array}{c}\text { Tidak ada } \\
\text { ditemukan }\end{array}$ & Negatif \\
\hline
\end{tabular}




\begin{tabular}{|c|c|c|c|}
\hline 9 & 14106055 & $\begin{array}{c}\text { Tidak ada } \\
\text { ditemukan }\end{array}$ & Negatif \\
\hline 10 & 14106056 & $\begin{array}{c}\text { Tidak ada } \\
\text { ditemukan }\end{array}$ & Negatif \\
\hline 11 & 14106057 & $\begin{array}{c}\text { Tidak ada } \\
\text { ditemukan }\end{array}$ & Negatif \\
\hline 12 & 14106058 & $\begin{array}{c}\text { Tidak ada } \\
\text { ditemukan }\end{array}$ & Negatif \\
\hline 13 & 14106059 & $\begin{array}{c}\text { Tidak ada } \\
\text { ditemukan }\end{array}$ & Negatif \\
\hline 14 & 14106060 & $\begin{array}{c}\text { Tidak ada } \\
\text { ditemukan }\end{array}$ & Negatif \\
\hline 15 & 14106061 & $\begin{array}{c}\text { Tidak ada } \\
\text { ditemukan }\end{array}$ & Negatif \\
\hline
\end{tabular}

\section{PEMBAHASAN}

Berdasarkan tabel identifikasi Neisseria gonorrhoeae pada PSK di Panti Sosial Mattirodeceng Makassar pada 15 sampel hasilnya tidak ditemukan (Negatif). Ada beberapa faktor yang dapat mempengaruhi hasil pemeriksaan yaitu pada proses pengambilan sampel, pada proses transpor spesimen, penanganan sampel dan pengobatan berkala yang dilakukan oleh pemerintah pada pekerja seks komersial.

Proses pengambilan sampel menggunakan speculum pada mulut rahim, swab lidi steril didiamkan beberapa saat dan diputar dengan searah jarum jam beberapa detik sebelum lidi kapas ditarik. Swab steril yang digunakan sebaiknya 2, satu untuk pengecatan gram dan yang satunya untuk biakan kultur. Swab steril yang digunakan sebaiknya menggunakan swab steril yang ujung lidi kapas yang diproses dengan arang atau ujung lidi Kalsium alginat atau Dacron. Jika lidi kapas pengambilan bahan khusus dan dibuat secara komersial ini tidak tersedia dan digunakan kapas lidi biasa spesimen harus diinokulasikan segera.

Gonore menyebabkan servisitis pada wanita. Gonore yang tidak diobati dapat menyebabkan epididimitis pada pria dan penyakit radang panggul (PID) pada wanita, yang dapat menyebabkan sekuele serius seperti infertilitas, kehamilan ektopik, dan nyeri panggul kronis. Jarang, infeksi gonokokal dapat menjadi invasif, mengarah ke infeksi gonokokal disebarluaskan (DGI), yang dapat menyebabkan sindrom gonokokal-dermatitis arthritis, artritis supuratif, endokarditis, dan meningitis. (Furuya R 2009).

Pada wanita, gejala pertama kali timbul $7-21$ hari setelah ia terinfeksi. Atau seringkali wanita yang terinfeksi tidak menunjukkan gejala apapun sampai berminggu - minggu bahkan berbulan bulan setelah ia terinfeksi, dan baru ketahuan setelah pria pasangannya diketahui terinfeksi kemudian ia ikut periksa. Kalaupun terdapat gejala pada wanita biasanya ringan.( Lai-King 2005) Akan tetapi pada beberapa kasus gejala yang biasanya timbul adalah sebagai berikut :

1. Keluarnya cairan hijau kekuningan dari vagina

2. Demam

3. Muntah - muntah

4. Rasa gatal dan sakit pada anus serta sakit ketika buang air besar, umumnya terjadi pada wanita dan homoseksual yang melakukan anal seks dengan pasangan yang terinfeksi

5. Rasa sakit pada sendi

6. Munculnya ruam pada telapak tangan

7. Sakit pada tenggorokan

Apabila gonoroe tidak diobati, Neisseria gonorrhoeae dapat menyebar ke aliran darah dan mengenai sendi, katup jantung atau otak. Konsekuensi yang paling umum dari gonoroe adalah infeksi serius pada irgan reproduksi wanita yang dapat menyebabkan infertilitas. Selain itu, kerusakan yang terjadi dapat menghambat perjalanan sel telur berkembang biak didalam saluran falopii atau yang disebut kehamilan di luar kandungan, suatu hal yang dapat mengancam nyawa sang ibu apabila tidak terdeteksi secara dini. Seorang wanita yang terinfeksi dapat menularkan penyakit kepada bayinya ketika bayi lahir. Pada pria apabila tidak ditangani secara serius dapat menyebabkan impotensi. Pengobatan yang dilakukan dengan pendekatan sindrom dapat mengakibatkan resistensi terhadap antibiotik tertentu sehingga mempersulit dalam hal pengobatan.

\section{KESIMPULAN}

Dari hasil pemeriksaan laboratorium terhadap 10 sampel pekerja seks komersial di Panti Sosial Mattirodeceng Makassar tidak ditemukan Neisseria gonorrhoeae.

\section{Saran}

Penularan penyakit gonoroe dapat dicegah dengan penggunaan kondom atau seks yang aman. Selain itu perlu terus waspada, karena setelah seseorang terinfeksi, tidak berarti selanjutnya ia menjadi kebal atau imun. Banyak orang terserang gonoroe lebih dari sekali. Penggunaan obat - 
obatan antibiotik yang tidak sesuai dengan aturan mengakibatkan Neisseria gonorrhoeae resisten sehingga lebih menyulitkan pengobatan.

Pencegahan jauh lebih baik dan lebih mudah dibandingkan dengan pengobatan. Hindarilah berganti pasangan. Kemudian bersikap setia terhadap pasangan juga merupakan tindakan yang baik untuk pencegahan penyakit ini.

UCAPAN TERIMA KASIH

Kepada yang terhormat :

1. Direktur Poltekkes Kemenkes Makassar yang telah memberikan izin dalam penelitian ini.

2. Ketua Jurusan Analis Kesehatan Poltekkes Makassar yang telah memberikan support dan izin untuk melaksanakan penelitian.

3. Kepala Balai Besar Laboratorium Kesehatan RI di Makassar yang telah memberikan izin tempat penelitian

4. Kepada Seluruh teman teman yang telah berpartisipasi dan membantu dalam penelitian ini.

\section{DAFTAR PUSTAKA}

Irianto K, 2007. Mikrobiologi menguak dunia mikroorganisme jilid 2,CV.Yrama widya, Bandung.

Lai-King Ng, Irene EM 2005; Canadian journal of infectious disease and medical mycrobiology

https://www.ncbi.nlm.nih.gov/pmc/articles/ PMC2095009/ di akses pada tanggal 10 Agustus 2017)

Janda WJ, Knapp JS. Neisseria and Moraxella catarrhalis In: Murray PR, Baron EJ, Pfaller $\mathrm{MA}$, Jorgensen $\mathrm{JH}$, Yolken $\mathrm{RH}$, eds. Manual of Clinical Microbiology, 8th edn. Washington: American Microbiology, 2003:585-608.

Society

LCDC Expert Working Group on Canadian Guidelines for Sexually Transmitted Diseases. Canadian STD Guidelines. Ottawa: Health Canada, 1998:57-58,140-9

Furuya R, Tanaka M. 2009, Neisseria gonorrhoeae infections, https://www. ncbi.nlm.nih.gov/pubmed/19177762 diakses pada tanggal 25 Mei 2017
Jawet, melnick, \& adelberg, 2013. Mikrobiologi kedokteran edisi 25, penerbit buku kedikteran EGC, jakarta

J.Vandepitta, J.Varhaogon,K.engbaek, P.Rohner, P.Plat, \& C.Ghouck, 2011, Prosedur laboratorium dasar untuk Bakteriologi Klinis, edisi 2, penerbit buku kedokteran EGC, Jakarta

Kementrian Kesehatan RI, 2011. Pedoman Nasional Penanganan Infeksi Menular Seksual 2011

Michael J. Pelczar, Jr., dan E.C.S Chan, 2012. Dasar - dasar mikrobiologi 2, universitas Indonesia, jakarta

Mikrobia.files.wordpress.com/2008/05/devina, Neisseria gonorrhoeae

Radji M,n2011, Buku ajar Mikrobiologi panduan mahasiswa farmasi \& kedokteran, penerbit buku kedokteran EGC, Jakarta 